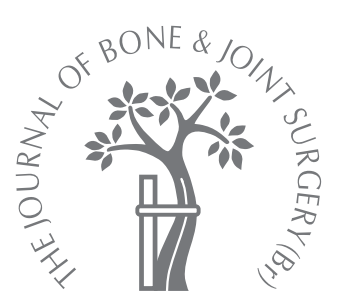

P. Moonot, N. Ashwood, M. Hamlet

From Queen's Hospital, Burton-onTrent, United Kingdom

\title{
Early results for treatment of three- and four- part fractures of the proximal humerus using the PHILOS plate system
}

\begin{abstract}
Secure fixation of displaced proximal fractures of the humerus is a challenging problem. A total of 32 patients with acutely displaced three- or four-part proximal fractures of the humerus were treated by open reduction and internal fixation using the proximal humeral internal locking system (PHILOS) plate. There were 23 women and nine men with a mean age of 59.9 years ( 18 to 87 ). Data were collected prospectively and the outcomes were assessed using the Constant score. The mean follow-up was for 11 months (3 to 24). In 31 patients $(97 \%)$ the fracture united clinically and radiologically at a mean of 10 weeks (8 to 24). The mean Constant score at final review was 66.5 (30 to 92). There was no significant difference in outcome when comparing patients aged more than 60 years (18 patients) with those aged less than 60 years (14 patients) ( $t$-test, $p=0.8443$ ). There was one case each of nonunion, malunion and a broken screw in the elderly population.

This plate provides an alternative method of fixation for fractures of the proximal humerus. It provides a stable fixation in young patients with good-quality bone sufficient to permit early mobilisation. Failure of the screws to maintain fixation in the elderly remains a problem.
\end{abstract}

The incidence of proximal fractures of the humerus is between $4 \%$ and $5 \%$ of all fractures. ${ }^{1}$ They occur most commonly in the elderly. In younger patients, high-energy trauma is the cause and displacement is often more severe. These patients usually have a fracturedislocation. $^{2}$ Most of these fractures, in younger patients as well as in the elderly, are stable and minimally displaced and can be treated conservatively. ${ }^{3}$ However, unstable displaced fractures have high morbidity, especially in older patients.

Secure fixation of displaced three- and fourpart fractures of the proximal humerus remains a problem. ${ }^{4-6}$ Various methods have been described, including Kirschner (K)-wires, external fixation, tension band fixation, Rush pins, intramedullary nails and plating. ${ }^{7,8}$ The proximal humeral internal locking system (PHILOS) plate (Synthes, Stratec Medical Ltd, Mezzovico, Switzerland) has been developed to improve screw fixation in osteoporotic bone and to minimise soft-tissue dissection. It combines the principles of fixation with a conventional plate with those of locking screws. The screw holes in the shaft can take either standard or locking screws. The plate is preshaped and contoured for the proximal humerus. No compression of the plate is required, which reduces the risk of loss of reduction and preserves the blood supply of the bone. Locking the screws into the plate ensures angular as well as axial stability and reduces the risk of loss of reduction. The locked interface also provides fixed stability, which helps to prevent subsidence in the metaphyseal areas. ${ }^{9}$

This prospective study was undertaken to evaluate the efficacy of the PHILOS plate in the treatment of displaced three- and four-part fractures of the proximal humerus.

\section{Patients and Methods}

Between January 2003 and December 2005, a total of 32 patients with displaced three- and four-part fractures of the proximal humerus had an open reduction with internal fixation using a PHILOS plate. There were nine men and 23 women with a mean age of 59.9 years (18 to 87 ). A total of 18 patients were aged more, and 14 less than 60 years. There were 23 patients injured in a simple fall, six in a road traffic accident, and three fell down stairs. A total of 20 patients had three-part fractures and 12 had four-part fractures.

The surgery in all cases was performed by a consultant surgeon (NA or $\mathrm{MH}$ ) under general anaesthesia with the patient in a 'beach chair' position. A deltopectoral approach was used 


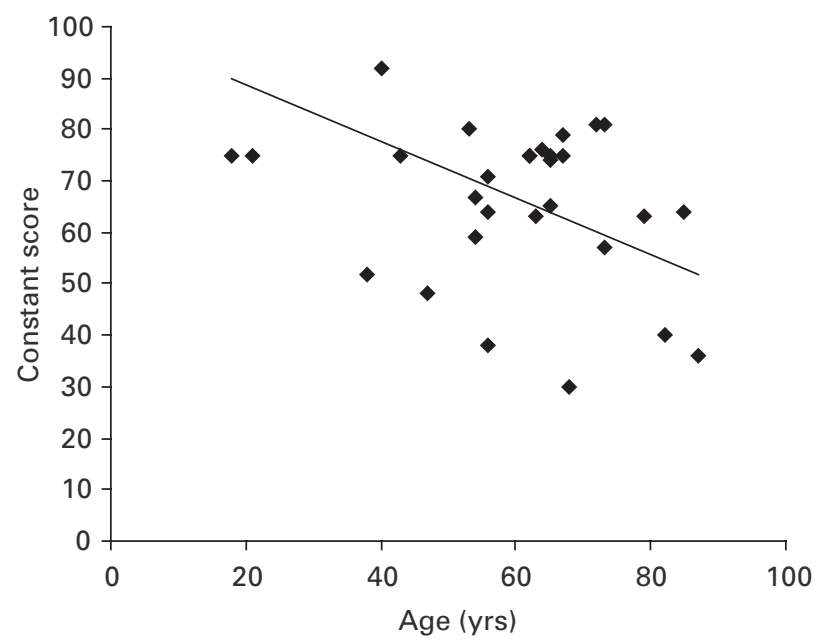

Fig. 1

Scatter plot of the age of the patient versus the Constant score, ${ }^{10}$ showing the line of best fit.

Table I. Age-related Constant scores ${ }^{10}$

\begin{tabular}{lll}
\hline \multirow{2}{*}{ Constant score } & \multicolumn{2}{l}{ Number of patients $(\%)$} \\
\cline { 2 - 3 } \cline { 2 - 3 } Age $<\mathbf{6 0}$ yrs & Age $>\mathbf{6 0}$ yrs \\
\hline$>75$ (excellent) & $6(43)$ & $9(50)$ \\
50 to 75 (satisfactory) & $6(43)$ & $6(33)$ \\
$<50$ (poor) & $2(14)$ & $3(17)$ \\
\hline
\end{tabular}

with minimal soft-tissue dissection. The biceps tendon was identified and retracted, and the fracture exposed between the tuberosities and behind the bicipital groove. If the greater tuberosity was displaced posteriorly, attempts were made to reduce it anatomically. Flexing the arm helped to reduce extension at the fracture site. The fracture was reduced and held temporarily with $\mathrm{K}$-wires. The reduction was checked fluoroscopically and then a PHILOS plate was applied using a minimum of four proximal locking screws. In two patients with poor bone stock, Allomatrix bone substitute (Wright Medical, Arlington, Tennessee) was used. In 29 patients, AO cortical screws were used to hold the plate on the humeral shaft. However, in three patients with severely osteoporotic bone, locking screws were used.

The wound was closed over a suction drain, which was removed after 24 hours. Post-operatively the arm was supported in a sling. Pendular movements were started from the first post-operative day and the shoulder was mobilised with active assisted exercises, followed after three weeks by active exercises.

All the patients were seen at two and six weeks and at three-month intervals until union was achieved. Assessment of shoulder function was by the Constant score. ${ }^{10}$
Callus formation and cortical continuity was observed on radiographs for evidence of radiological union. The functional outcome in patients aged more than 60 years was compared with that of those who were younger. The mean follow-up was for 11 months ( 3 to 24). The radiographs were reviewed retrospectively at the end of the study. Student's $t$-test with $95 \%$ confidence intervals (CI) was used to compare the groups, and statistical significance was set at $\mathrm{p}=0.05$.

\section{Results}

No patients were lost to follow-up. A total of 31 fractures $(97 \%)$ united clinically and radiologically. The mean time to union was 10 weeks ( 8 to 24). The mean Constant score at final review was 66.5 (30 to 92). The relationship between outcome and age is shown in Figure 1 and Table I. A total of 27 patients $(84 \%)$ had an excellent or satisfactory result, but in five $(16 \%)$ the outcome was poor. The mean score in patients aged more than 60 years was 66.1 (30 to 81 ) and in those aged less than 60 years it was 67.1 (38 to 92 ). This difference was not statistically significant ( $t$-test, $\mathrm{p}=0.8443)$.

Complications. The complications are summarised in Table II. There was one superficial wound infection, which was treated with oral antibiotics, and one patient had a transient axillary nerve palsy. Three patients (9\%) had symptoms of impingement requiring removal of the plate in one and of prominent screws in two. There was malunion in two patients $(6 \%)$; both had a four-part fracture and a poor outcome. A distal screw broke in one case $(3 \%)$ with separation of the plate from the bone. However, the alignment of the fracture remained satisfactory and no further treatment was required (Fig. 2). One patient $(3 \%)$ developed nonunion and avascular necrosis of the humeral head (Fig. 3). Both these complications occurred in a 68-year-old woman who had sustained a three-part fracture of the proximal humerus due to lowenergy trauma. The plate was fixed with nine locking screws in the head and bicortical self-tapping screws in the shaft. Post-operative radiographs showed a good reduction with all the proximal locking screws in the humeral head. At six weeks the radiographs showed loss of fixation, collapse of the humeral head, and penetration of the proximal locking screws into the articular surface of the humeral head. These screws were taken out as a day procedure. The fracture collapsed into varus (Fig. 3). A hemiarthroplasty was subsequently undertaken five months after PHILOS plate fixation.

\section{Discussion}

This study suggests that treatment with the PHILOS plate may give a satisfactory outcome in patients with displaced three- and four-part fractures of the proximal humerus. The fixation is usually stable enough to allow early mobilisation. 
Table II. Implant-related complications

\begin{tabular}{lllll}
\hline Patient & Age (yrs) & Type of fracture & Complications & Treatment \\
\hline 1 & 68 & 3-part & $\begin{array}{l}\text { Nonunion and avascular necrosis } \\
\text { Transient axillary nerve palsy }\end{array}$ & Hemiarthroplasty \\
2 & 82 & 3-part & Broken distal screw & No further treatment \\
3 & 87 & 4-part & Malunion due to loss of purchase in the humeral head & No further treatment \\
4 & 47 & 4-part & Malunion & No further treatment \\
5 & 40 & 3-part & Impingement & Plate removed \\
6 & 72 & 3-part & Prominent proximal screws & Removal of screws \\
7 & 67 & 4-part & Prominent proximal screws & Removal of screws \\
\hline
\end{tabular}

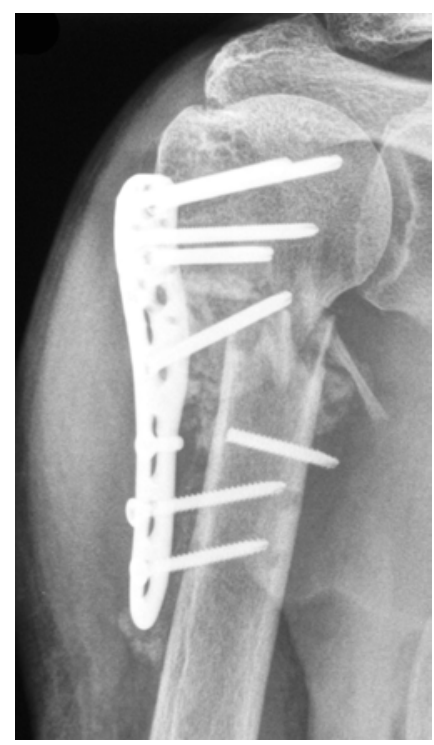

Fig. 2

Anteroposterior radiograph three months after fixation of a three-part proximal humeral fracture, with a broken distal locking screw and backing-out of the PHILOS plate.

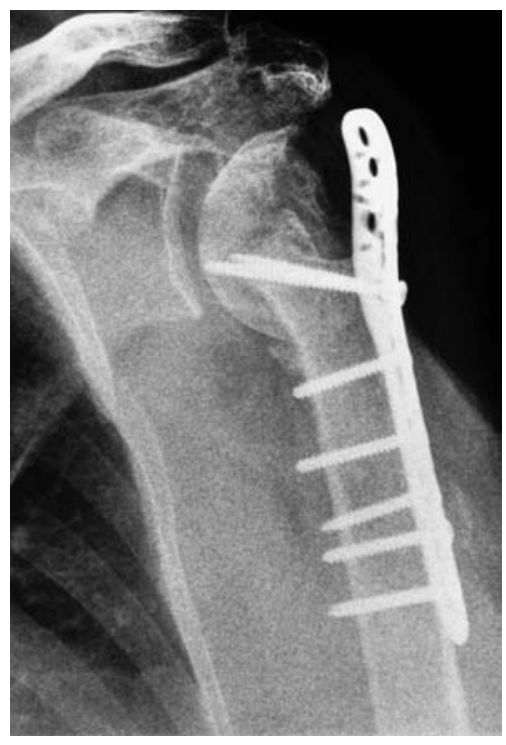

Fig. 3

Anteroposterior radiograph of the left shoulder after removal of the proximal locking screws, with evidence of nonunion and avascular necrosis of the head of the humerus.
Tension band wiring has been the most common method of fixation for these fractures, but some studies have shown no difference in functional outcome between those patients treated by tension band wiring and those treated nonoperatively. $^{4,11}$

AO T-plates (AO-ASIF, Davos, Switzerland) and the clover-leaf plate give poor results in patients with inadequate bone stock and have a complication rate including screw loosening, subacromial impingement and avascular necrosis, of approximately $40 \%{ }^{5,8}$ Displaced four-part fractures in the elderly may be treated by hemiarthroplasty. Pain relief is good, but function and range of movement are less predictable. ${ }^{6,12}$ There is some evidence that the outcome may not depend on the design of the prosthesis. ${ }^{13}$ Good results have been reported following the use of reverse shoulder arthroplasty. ${ }^{14}$

The Polarus nail (Acumed Inc., Beaverton, Oregon) has been used to treat such fractures. ${ }^{15,16}$ It gives good results but the choice of site of entry can be difficult and it may cause lateral metaphyseal comminution. ${ }^{15}$ Satisfactory and excellent functional results using this nail were reported in $80 \%$ of patients by Rajasekhar et al. ${ }^{16}$ However, most of the patients in their series (23 of 27) had only two-part fractures.

The Plan Tan humerus fixator plate (Plan Tan Medizintecknik $\mathrm{GmbH}$, Lambrechtshagen, Germany) may also be used, but Sadowski et $\mathrm{al}^{17}$ reported a $100 \%$ failure rate in elderly patients. Penetration of the proximal screws through the head during impaction was the main complication.

There are only two studies in the English literature describing the use of the PHILOS plate. ${ }^{18,19}$ Bjorkenheim et al ${ }^{18}$ described a study of 72 patients in whom this plate was used: there was a mean Constant score of 72 at follow-up after six months. They particularly recommended use of the plate for the treatment of proximal humeral fractures in patients with poor bone quality. They reported two cases $(3 \%)$ of nonunion, three cases $(4 \%)$ of avascular necrosis, and two implant failures $(3 \%)$ with loss of fixation. 
Koukakis et $\mathrm{al}^{19}$ published a series of 20 patients with two-, three- and four-part fractures treated with this plate. The mean Constant score was 76 after six months. They described two complications; one elderly patient in whom the plate had separated from the humeral diaphysis and another patient with symptoms from prominent metalwork. There was no difference in functional outcome between the younger ( $<65$ years) and the older ( $>65$ years) patients. The authors stressed the importance of anatomical reduction of the fracture and correct surgical technique.

In our study all the fractures united except in one patient $(3 \%)$, who had nonunion and avascular necrosis of the humeral head. One patient required removal of the plate and two required removal of screws. The mean Constant score in this study was 66.5. Although this was lower than in the other series ${ }^{19}$ we only included three- and four-part fractures.

The PHILOS plate can be a very rigid construct if locking screws are used both proximally and distally. This can produce a stress concentration at the surgical neck of the hummerus. This can be reduced by using standard screws in the humeral shaft, which reduces the rigidity of the construct. In osteoporotic bone, bicortical self-tapping locking screws should be used so as to increase the working length of the screw and avoid a potential problem at the interface between the screw thread and the bone. Increasing the distance between the plate and the bone can also reduce the stability of the construct. ${ }^{9,20}$

Although small, our study shows that the PHILOS plate can give good results in the treatment of displaced threeand four-part fractures. In poor bone stock, we advocate packing of the humeral head and the shaft of the humerus with bone graft or bone substitutes.

No benefits in any form have been received or will be received from a commercial party related directly or indirectly to the subject of this article.

\section{References}

1. Habermeyer P, Schweiberer L. Fractures of the proximal humerus. Orthopade 1989;18:200-7 (in German).
2. Flatow EL. Fractures of the proximal humerus. In: Bucholz RW, Heckman JD, eds. Rockwood and Greens fractures in adults. Vol. 1. Philadelphia: Lippincott, Williams and Wilkins, 2001:997-1035.

3. Young TB, Wallace WA. Conservative treatment of fractures and fracture-dislocations of the upper end of the humerus. J Bone Joint Surg [Br] 1985;67-B:373-7.

4. Zyto K, Ahrengart L, Sperber A, Tornkvist H. Treatment of displaced proximal humeral fractures in elderly patients. J Bone Joint Surg [Br] 1997;79-B:412-17.

5. Rees J, Hicks J, Ribbans W. Assessment and management of three- and four-part proximal humeral fractures. Clin Orthop 1998;353:18-29.

6. Goldman RT, Koval KJ, Cuomo F, Gallagher MA, Zuckerman JD. Functional outcome after humeral head replacement for acute three- and four-part proximal humeral fractures. J Shoulder Elbow Surg 1995;4:81-6.

7. Kristiansen B, Kofoed H. External fixation of displaced fractures of the proximal humerus: technique and preliminary results. J Bone Joint Surg [Br] 1987;69-B:643-6.

8. Kristiansen B, Christiansen SW. Plate fixation of proximal humeral fractures. Acta Orthop Scand 1986;57:320-3.

9. Gautier E, Sommer C. Guidelines for the clinical application of the LCP. Injury 2003;34(Suppl 2):63-76.

10. Constant CR, Murley AH. A clinical method of functional assessment of the shoulder. Clin Orthop 1987;214:160-4

11. Ilchmann T, Ochsner PE, Wingstrand $\mathbf{H}$, Jonsson $\mathbf{K}$. Non-operative treatment versus tension-band osteosynthesis in three- and four-part proximal humeral fractures: a retrospective study of 34 fractures from two different trauma centers. Int Orthop 1998;22:316-20.

12. Moeckel BH, Dines DM, Warren RF, Altchek DW. Modular hemiarthroplasty for fractures of the proximal part of the humerus. J Bone Joint Surg [Am]1992:74-A:884-

13. Leow M, Heitkemper S, Parsch D, Schneider S, Rickert M. Influence of the design of the prosthesis on the outcome after hemiarthroplasty of the shoulder in displaced fractures of the head of the humerus. J Bone Joint Surg [Br]2006;88-B:345-50.

14. Bufquin T, Hersan A, Hubert L, Massin P. Reverse shoulder arthroplasty for the treatment of three- and four-part fractures of the proximal humerus in the elderly: a prospective review of 43 cases within a short-term follow-up. J Bone Joint Surg [Br] 2007:89-B:516-20.

15. Agel J, Jones CB, Sanzone AG, Camuso M, Henley MB. Treatment of proximal humeral fractures with Polarus nail fixation. J Shoulder Elbow Surg 2004:13:191-5.

16. Rajasekhar C, Ray PS, Bhamra MS. Fixation of proximal humeral fractures with the Polarus nail. J Shoulder Elbow Surg 2001;10:7-10.

17. Sadowski C, Riand N, Stern R, Hoffmeyer P. Fixation of fractures of the proximal humerus with the PlantTan humerus fixator plate: early experience with a new implant. J Shoulder Elbow Surg 2003;12:148-51.

18. Bjorkenheim JM, Pajarinen J, Savolainen V. Internal fixation of proximal humeral fractures with a locking compression plate: a retrospective evaluation of 72 patients followed for a minimum of 1 year. Acta Orthop Scand 2004;75:741-5.

19. Koukakis A, Apostolou CD, Taneja T, Korres DS, Amini A. Fixation of proximal humerus fractures using the PHILOS plate: early experience. Clin Orthop 2006;442:115-20.

20. Wagner M. General principles for the clinical use of the LCP. Injury 2003;34/Suppl 2):31-42. 